University of Nebraska - Lincoln

DigitalCommons@University of Nebraska - Lincoln

6-1-2021

\title{
An Evaluation of Body-grip Trap Trigger Configurations for Reducing River Otter Take Incidental to Beaver Trapping
}

\author{
Alec J. Sundelius \\ USDA Animal and Plant Health Inspection Service (APHIS), Alec.J.Sundelius@usda.gov \\ Nicholas Forman \\ Wisconsin Department Natural Resources \\ Nathan M. Roberts \\ Wisconsin Department Natural Resources \\ Shawn T. Rossler \\ Wisconsin Department Natural Resources \\ David B. Ruid \\ USDA Animal and Plant Health Inspection Service (APHIS) \\ Follow this and additional works at: https://digitalcommons.unl.edu/icwdm_usdanwrc

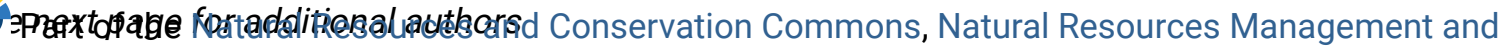 \\ Policy Commons, Other Environmental Sciences Commons, Other Veterinary Medicine Commons, \\ Population Biology Commons, Terrestrial and Aquatic Ecology Commons, Veterinary Infectious Diseases \\ Commons, Veterinary Microbiology and Immunobiology Commons, Veterinary Preventive Medicine, \\ Epidemiology, and Public Health Commons, and the Zoology Commons
}

Sundelius, Alec J.; Forman, Nicholas; Roberts, Nathan M.; Rossler, Shawn T.; Ruid, David B.; and Willging, Robert C., "An Evaluation of Body-grip Trap Trigger Configurations for Reducing River Otter Take Incidental to Beaver Trapping" (2021). USDA Wildlife Services - Staff Publications. 2516.

https://digitalcommons.unl.edu/icwdm_usdanwrc/2516

This Article is brought to you for free and open access by the U.S. Department of Agriculture: Animal and Plant Health Inspection Service at DigitalCommons@University of Nebraska - Lincoln. It has been accepted for inclusion in USDA Wildlife Services - Staff Publications by an authorized administrator of DigitalCommons@University of Nebraska - Lincoln. 


\section{Authors}

Alec J. Sundelius, Nicholas Forman, Nathan M. Roberts, Shawn T. Rossler, David B. Ruid, and Robert C. Willging 


\title{
An Evaluation of Body-grip Trap Trigger Configurations for Reducing River Otter Take Incidental to Beaver Trapping
}

\author{
ALEC J. SUNDELIUS, ${ }^{1}$ U.S. Department of Agriculture, Animal and Plant Health Inspection Service, Wildlife Services, 3654 Nursery Road, \\ Rbinelander, WI 54501, USA \\ NICHOLAS FORMAN, ${ }^{2}$ Wisconsin Department of Natural Resources, 2801 Progress Road, Madison, WI 53716, USA \\ NATHAN M. ROBERTS, ${ }^{3}$ Wisconsin Department of Natural Resources, 107 Sutliff Avenue, Rbinelander, WI 54501, USA \\ SHAWN T. ROSSLER, Wisconsin Department of Natural Resources, 101 South Webster Street, Madison, WI 53703, USA \\ DAVID B. RUID, U.S. Department of Agriculture, Animal and Plant Health Inspection Service, Wildife Services, 3654 Nursery Road, Rhinelander, \\ WI 54501, USA \\ ROBERT C. WILlgING, U.S. Department of Agriculture, Animal and Plant Health Inspection Service, Wildife Services, 3654 Nursery Road, \\ Rbinelander, WI 54501, USA
}

\begin{abstract}
River otter (Lontra canadensis) populations in North America have been the focus of significant restoration efforts. Wildlife management agencies, concerned about the unintentional take of river otters incidental to beaver (Castor canadensis) trapping, may recommend techniques to avoid capturing river otters. River otter avoidance techniques that are ineffective or diminish trap performance for beavers are undesirable. We conducted a field evaluation in 2015 and 2016 in Wisconsin to assess how two trigger configurations (offset and center) on body-grip traps would affect the incidental capture rate of river otters during beaver trapping. We also evaluated effects of each configuration on beaver capture rates, body lengths, and anatomical locations of trap-jaw strikes. We used size 330 body-grip traps equipped with identical triggers and alternated between trigger configurations during beaver damage management activities. We captured 8 river otters with each trap trigger configuration. Trap-jaw strikes on beavers differed between trigger configurations, with offset triggers resulting in more abdomen strikes and center triggers causing more cervical vertebrae strikes. We found that an offset trigger configuration did not reduce incidental take of otters and was less effective for trapping beavers. (C) 2021 The Wildlife Society. This article has been contributed to by US Government employees and their work is in the public domain in the USA.
\end{abstract}

KEY WORDS beaver, best management practices, Castor canadensis, incidental take, Lontra canadensis, river otter, trap, trapping, trigger placement, Wisconsin.

The North American beaver (Castor canadensis) is an herbivorous, semi-aquatic mammal that can significantly alter riparian landscapes by impounding water, flooding surrounding uplands, felling trees, and burrowing (Collen and Gibson 2001). Beavers conflict with humans when their activities flood roadways, agricultural fields, and damage timber resources (Taylor et al. 2017, Tremblay et al. 2017). In the upper Midwest, beaver impoundments may negatively impact cold water ecosystems by causing siltation of trout spawning habitat, warming water temperatures, and

Received: 18 March 2019; Accepted: 20 October 2020

Published: 14 May 2021

${ }^{1}$ E-mail: Alec.J.Sundelius@usda.gov

${ }^{2}$ Current affiliation: New Mexico Department of Game and Fish, 1 Wildlife Way, Santa Fe, NM 87507, USA

${ }^{3}$ Current affiliation: Conservation and Wildlife Management Program, College of the Ozarks, Point Lookout, MO 65726, USA creating barriers to fish migration (Collen and Gibson 2001, Avery 2002). The United States Department of Agriculture, Animal and Plant Health Inspection Service, Wildlife Services (USDA-WS), in partnership with the Wisconsin Department of Natural Resources (WDNR) and other local governments, manage beavers in Wisconsin to protect cold water ecosystems, roadways, wild rice lakes, wildlife impoundments, and railroads. Trapping is an effective management tool used for beaver management (Collen and Gibson 2001, Ruid 2003, Ribic et al. 2017). The size 330 body-grip trap, a rotating-jaw animal trap, is the most commonly-used trap by licensed beaver trappers (Responsive Management 2015). The size 330 body-grip trap typically has a jaw spread of $25.4 \mathrm{~cm}$ and is designed to kill quickly and humanely (Association of Fish and Wildlife Agencies 2016). Most beavers harvested by licensed trappers (65\%) or removed by USDA-WS (68\%) in Wisconsin are captured with body-grip traps (U.S. Department of Agriculture 2017, Dhuey and Rossler 2018a). 
The river otter (Lontra canadensis) can be vulnerable to unregulated harvest and has been the focus of significant restoration efforts (Swimley et al. 1999, Raesly 2001, Erb et al. 2018). There is a need to minimize incidental river otter take associated with beaver trapping (Swimley et al. 1999). Wisconsin has a large, stable river otter population but harvest tag availability is limited, and the season can be subject to early closure (Dhuey and Rossler 2018b, Roberts 2018). River otters are captured incidental to beaver trapping because both species occupy similar habitats, are similar in size, and move through habitat in a similar manner (Swimley et al. 1999, Kruuk 2006, Reid 2006, Bieber et al. 2018, Rutter et al. 2018). Consequently, most river otters harvested by licensed trappers $(82 \%)$ and incidentally taken by USDA-WS (85\%) during beaver management activities in Wisconsin are caught in body-grip traps (U.S. Department of Agriculture 2017, Dhuey and Rossler 2018a). To address the concern with river otters being incidentally captured with 330 body-grip traps set for beavers, Gotie et al. (2000) evaluated whether specific trigger types and configurations could reduce undesirable take. Trigger configurations were evaluated on beavers and river otters in an artificial raceway using traps that were clamped in the open position. Gotie et al. (2000) concluded that traps with two-way triggers (triggers that only fire with forward pressure), with trigger wires joined together and placed in an offset configuration, fired fewer times on river otters than other trigger configurations assessed. Presumably, river otters can pass through traps with offset triggers while beavers cannot. Gotie et al. (2000) evaluated the offset versus center trigger configurations in a field setting using functioning traps set by licensed trappers, and found no difference in the number of cervical catches or capture rates for beavers between the 2 trigger configurations. One river otter was captured in each trigger configuration (Gotie et al. 2000).

The offset configuration is listed as a river otter avoidance technique in the Best Management Practices for Trapping Beaver and River Otter in the United States (Association of Fish and Wildlife Agencies 2014, 2016) and has been adopted by NYSDEC and other state wildlife agencies (Ohio Department of Natural Resources 2008, Minnesota Department of Natural Resources 2010, North Dakota Game and Fish Department 2016, New Jersey Division of Fish and Wildlife 2018, Indiana Department of Natural Resources 2019, NYSDEC 2019). Whereas the offset configuration is recommended for licensed trappers, only Gotie et al. (2000) have evaluated its efficacy in reducing incidental take of river otters during beaver trapping. Our objectives were to evaluate the influence that an offset traptrigger configuration would have on reducing incidental capture of river otters, capture rates of beavers, body lengths of beavers, and anatomical locations of trap-jaw strikes on captured beavers.

\section{STUDY AREA}

We conducted our study in 15 northern Wisconsin counties (Barron, Bayfield, Burnett, Douglas, Florence, Forest,
Langlade, Marinette, Oconto, Oneida, Polk, Price, Rusk, Sawyer, and Washburn). The study area fell within the Laurentian Mixed Forest Province of the Warm Continental Division (Albert 1995, Bailey 1995). Northern Wisconsin was subject to strong seasonal contrasts in temperature with a cold, snowy winters, warm summers, and ample precipitation throughout the year. The Laurentian Mixed Forest Province was comprised of mixed stands of conifers and deciduous species, pure deciduous forest, and pure coniferous forest (Albert 1995, Bailey 1995). The forests were dominated by maples (Acer spp.), aspen (Populus spp.), northern red oak (Quercus rubra), basswood (Tilia americana), red pine (Pinus resinosa) and white pine (Pinus strobus) (Perry et al. 2004). The 15 counties within the study area encompassed $~ 38 \%$ of the total wetland acreage in Wisconsin, including thousands of lakes and thousands of miles of streams and rivers that accounted for $38 \%$ of Wisconsin's trout stream mileage (Martin 1965, WDNR 2002, WDNR 2012).

\section{METHODS}

Ten USDA-WS Wildlife Specialists were provided with commercially available 330 sized body-grip traps (Oneida Victor $^{\circledR}$, Cleveland, Ohio, USA) with a $25.4 \mathrm{~cm}$ jaw spread. Traps were equipped with 2-way bolt-on triggers (Adirondack Outdoor Company ${ }^{\circledR}$, Lewis, New York, USA) with trigger wires joined with a ferrule. Triggers were on top of the trap jaws and were either placed in the center or within $5 \mathrm{~cm}$ of the vertical jaw. Beaver traps were set in suitable locations and trigger configurations were alternated between traps during routine beaver damage management activities. At least $50 \%$ of each trap was submerged in water in accordance with state law. Specialists were not restricted to specific set types, baits or lures. A set is the immediate area surrounding a trap that has been manipulated to camouflage the trap and attract or funnel the target animal.

In Northern Wisconsin the harvest season for river otters and beavers runs from the first Saturday in November through 30 April. We collected data on the number of captures by species, set date, capture date, trigger configuration, beaver body length (nose to vent), and anatomical location of trap-jaw strike. Strike locations were recorded as either cervical (neck), double (caught by both trap jaws), or hip (abdomen). Double strikes can be lethal but are less precise than cervical strikes and indicate the animal was able to fit more of its body through the trap prior to capture. Data were collected 6 April 2015-30 April 2015 and 7 April 2016-6 May 2016 when beavers are removed from coldwater streams by USDA-WS during spring dispersal (Van Deelen 1991, Sun et al. 2000). Licensed trappers also target dispersing beavers in April. Unlike in some conventional damage situations, all attractants, trap locations, and set types used by USDA-WS during this period are consistent with the methods used by licensed trappers. We assumed beavers' responsiveness to USDA-WS trap sets would be consistent with their responsiveness to trap sets of licensed trappers. Capture procedures were part of a study plan approved by the WDNR and USDA-WS and adhered to the 
Best Management Practices for Trapping Beaver in the United States (Association of Fish and Wildlife Agencies 2016) in compliance with state law.

We used Pearson's $\chi^{2}$ to test for differences in frequency of captures (beaver, river otter, and other) in the two trigger configurations. For beaver captures, we also used Pearson's $\chi^{2}$ to test for differences in frequency of anatomical strike locations (cervical, double, or hip). In addition, for beaver captures, we used a Kruskal-Wallis test to analyze differences in body length between the two trigger configurations after testing for normality of those data using a ShapiroWilk test. For beaver and river otter captures, we used a two-tailed $t$-test to analyze differences in the number of days between captures, by species, comparing the two trigger configurations. All comparisons for the effect of trigger configuration were tested using summed data across both years, ignoring for any effect of year on the variables. We used program R (v.3.3.1, R Core Team 2018) for all statistical analyses and set the alpha value at 0.05 .

\section{RESULTS}

A total of 119 (62 offset trigger, 57 center trigger) study traps were set in 2015 and 134 (61 offset trigger, 73 center trigger) were set in 2016. Ninety-seven beavers, 7 river otters, 3 muskrats (Ondatra zibethicus), and one raccoon (Procyon lotor) were captured in 2015. One hundred and twenty beavers, 9 river otters, and 2 muskrats were captured in 2016. There were 127 captures in traps with triggers in the center configuration and 112 captures in traps with triggers in the offset configuration (Table 1). We found no difference between years in the numbers of each species captured $\left(\chi_{4}^{2}=1.29, P=0.73\right)$. We found no difference in total numbers of species captured between trigger configurations for all species $\left(\chi_{4}^{2}=1.30, P=0.73\right)$. Mean body length of beaver did not differ between the center $(\bar{x}=63.6 \mathrm{~cm}, \mathrm{SD}=7.4 \mathrm{~cm})$ and the offset configuration's $(\bar{x}=64.9 \mathrm{~cm}, \quad \mathrm{SD}=8.4 \mathrm{~cm}) \quad$ (Kruskal-Wallis $\mathrm{H}=2.08$, $\mathrm{df}=1, P=0.15)$. We detected a difference in the frequency of strike locations for beaver between the two trigger configurations $\left(\chi_{4}^{2}=9.98, P<0.001\right)$, with the center trigger configuration causing more cervical strikes and fewer hip strikes than the offset configuration (Table 2). We detected a difference in the number days between beaver captures for the center $(\bar{x}=5.4, \mathrm{SD}=4.1)$ and offset trigger $(\bar{x}=6.2$, $\mathrm{SD}=5.6)$ configurations with the center trigger configuration having the higher beaver catch rate, although this difference was not statistically significant $(t=1.27$, $\mathrm{df}=237, P=0.21)$. Similarly, there was a difference detected for the number of days between river otter captures

Table 1. Number of captures by species for two body-grip trap trigger configurations in northern Wisconsin, USA, 2015-2016.

\begin{tabular}{lcccc}
\hline & & \multicolumn{2}{c}{ Species } & \\
\cline { 3 - 4 } $\begin{array}{l}\text { Trigger } \\
\text { configuration }\end{array}$ & Beaver & $\begin{array}{l}\text { River } \\
\text { Otter }\end{array}$ & Muskrat & Raccoon \\
\hline Offset & 101 & 8 & 2 & 1 \\
Center & 116 & 8 & 3 & 0 \\
\hline
\end{tabular}

Table 2. Frequencies of trap jaw strike locations on beaver for two bodygrip trap trigger configurations in northern Wisconsin, USA, 2015-2016.

\begin{tabular}{lccc}
\hline & \multicolumn{3}{c}{ Trap jaw strike location } \\
\cline { 2 - 4 } Trigger Configuration & Cervical & Double & Hip \\
\hline Offset & 53 & 30 & 18 \\
Center & 81 & 27 & 8 \\
\hline
\end{tabular}

between the center $(\bar{x}=7.4, \mathrm{SD}=5.5)$ and offset trigger $(\bar{x}=6.4, \mathrm{SD}=5.3)$ which was not statically significant $(t=1.43, \mathrm{df}=237, P=0.35)$.

\section{DISCUSSION}

We found that offset triggers did not reduce the number of incidental river otter captures relative to a center trigger configuration. Our trap sites were in natural environments, allowing river otters to move irregularly using their limbs, body, and tail in a variety of swim modes (Liers 1951, Sheldon and Toll 1964, Fish 1994, Kruuk 2006). In contrast, Gotie et al. (2000) conducted work on river otters that were restricted to linear movements in an artificial raceway. We suggest that irregular movements increase the likelihood a river otter will contact an offset trap trigger and may have contributed to the ineffectiveness of the offset trigger configuration in reducing incidental river otter captures. The efficacy of the offset trigger should be tested with body-grip traps with a jaw spread larger than $25.4 \mathrm{~cm}$.

Cervical strikes are more effective than hip strikes because they kill beavers more efficiently (Zelin et al. 1983). A beaver can likely fit more of their body through a trap with an offset trigger prior to the trap firing, resulting in more hip strikes. Thus, the offset trigger configuration we used reduced the effectiveness of size 330 body-grip traps when targeting beavers by reducing the number of cervical strikes and increasing the number of hip strikes. We note that our results may not be applicable during winter beaver trapping due to differences in beaver and otter behaviors and trap set type use (Muller-Schwarze and Sun 2003, Kruuk 2006).

\section{MANAGEMENT IMPLICATIONS}

We recommend wildlife agencies discontinue using the offset trigger configuration as a technique for avoiding incidental take of river otters in beaver traps, since we did not observe a reduction in river otter taken and fewer lethal strikes occurred. Wildlife agencies should emphasize other techniques that may reduce incidental river otter take such as avoiding high probability travel corridors and/or minimizing the duration of beaver trapping efforts at each site (Taylor et al. 2017). Wildlife managers and licensed trappers should also consider using more selective beaver traps to avoid river otter, such as snares and foothold traps whenever practical (Mason et al. 1983, Ruid 2003).

\section{ACKNOWLEDGMENTS}

We would like to thank USDA-WS personnel J. Carbonari, M. Edwards, M. Gross, J. Johnson, T. Karau, M. Kerr, J. Nuce, M. Petrie, K. Thiel, J. Zesiger, and S. Zesiger for their participation and assistance with this study. We would 
also like to thank J. Taylor, D. Drake, S. Brainerd (Associate Editor), A. Knipps (Editorial Assistant), and two anonymous reviewers for reviewing this manuscript. Mention of commercial products does not imply recommendation or endorsement by the U.S. Department of Agriculture.

\section{LITERATURE CITED}

Albert, D. A. 1995. Regional landscape ecosystems of Michigan, Minnesota, and Wisconsin: a working map and classification. U.S. Forest Service, North Central Experiment Station, Saint Paul, Minnesota, USA.

Association of Fish and Wildlife Agencies. 2014. Best management practices for trapping otter in the United States. <https://www. fishwildlife.org/application/files/8015/2105/3073/Otter_BMP_2014_F. pdf $>$. Accessed 17 Jun 2019.

Association of Fish and Wildlife Agencies. 2016. Best management practices for trapping beaver in the United States. <https://www. fishwildlife.org/application/files/2615/2105/0542/Beaver_BMP_2016. pdf $>$. Accessed 16 Jan 2019.

Avery, E. L. 2002. Fish community and habitat responses in a northern Wisconsin brook trout stream 18 years after beaver dam removal. Statewide Fisheries and Habitat Research Project F-95-P. Wisconsin Department of Natural Resources, Madison, USA.

Bailey, R. G. 1995. Description of the ecoregions of the United States. U.S. Forest Service, Rocky Mountain Research Station, Fort Collins, Colorado, USA.

Bieber, N. R., S. P. Wilson, and C. R. Allen. 2018. River otter distribution in Nebraska. Wildlife Society Bulletin 42:136-143.

Collen, P., and R. J. Gibson. 2001. The general ecology of beavers (Castor spp.), as related to their influence on stream ecosystems and riparian habitats, and the subsequent effects on fish-a review. Reviews in Fish Biology and Fisheries 10:439-461.

Dhuey, B., and S. Rossler. 2018a. Beaver trapping questionnaire. Wisconsin wildlife surveys. Wisconsin Department of Natural Resources, Madison, USA.

Dhuey, B., and S. Rossler. 2018b. Otter harvest. Wisconsin wildlife reports. Wisconsin Department of Natural Resources, Madison, USA.

Erb, J., N. M. Roberts, and C. Dwyer. 2018. An otterly successful restoration. The Wildlife Professional May-June:45-49.

Fish, F. E. 1994. Association of propulsive swimming mode with behavior in river otters (Lutra canadensis). Journal of Mammalogy 75:989-997.

Gotie, R., M. Kautz, M. Brown, and E. Kautz. 2000. Selectivity with \#330 conibears. The Trapper and Predator Caller October:27-29.

Indiana Department of Natural Resources. 2019. Avoiding otter while trapping beaver and raccoon. Indiana Department of Natural Resources, Indianapolis, USA. <https://www.in.gov/dnr/fishwild/3353.htm>. Accessed 17 June 2019.

Kruuk, H. 2006. Otters: ecology, behavior, and conservation. Oxford University Press, New York, New York, USA.

Liers, E. E. 1951. Notes on the river otter (Lutra Canadensis). Journal of Mammalogy 32:1-9.

Martin, L. 1965. The physical geography of Wisconsin. Third Edition. University of Wisconsin Press, Madison, USA.

Mason, C. E., E. A. Gluesing, and D. H. Arner. 1983. Evaluation of snares, leg-hold, and conibear traps for beaver control. Proceedings of the Southeastern Association of Fish and Wildlife Agencies 37:201-209.

Minnesota Department of Natural Resources. 2010. River otter avoidance techniques. Minnesota Department of Natural Resources, Saint Paul, USA.

Muller-Schwarze, D., and L. Sun. 2003. The beaver: natural history of a wetlands engineer. Cornell University Press, New York, New York, USA.

New Jersey Division of Fish and Wildlife. 2018. 2018-19 NJ beaver and otter trapping season information. New Jersey Division of Fish and Wildlife, Trenton, USA. <https://www.njfishandwildlife.com/pdf/2018/ beavott_regs18.pdf $>$. Accessed 17 June 2019.
New York Department of Environmental Conservation [NYSDEC]. 2019. Trigger regulations for beaver trappers. New York Department of Environmental Conservation, Albany, USA. <https://www.dec.ny.gov/ outdoor/9208.html>. Accessed 16 Jan 2019.

North Dakota Game and Fish Department. 2016. River otters in North Dakota: trapping avoidance techniques. North Dakota Game and Fish Department, Bismarck, USA. <https://gf.nd.gov/sites/default/files/ publications/otter_trapping_avoidance.pdf $>$. Accessed 25 Jan 2019.

Ohio Department of Natural Resources. 2008. Techniques to avoid trapping river otters. Ohio Department of Natural Resources, Columbus, USA.

Perry, C. H., V. A. Everson, I. K. Brown, J. Cummings-Carlson, S. E. Dahir, E. A. Jepsen, J. E. Kovach, M. D. LaBissoniere, T. R. Mace, E. A. Padley, et al. 2004. Wisconsin's forests. Research Bulletin NRS-23. U.S. Forest Service, Northern Research Station, Newton Square, Pennsylvania, USA.

Raesly, E. J. 2001. Progress and status of river otter reintroduction projects in the United States. Wildlife Society Bulletin 29:856-862.

$\mathrm{R}$ Core Team. 2018. R version 3.3.1: a language and environment for statistical computing. R Foundation for Statistical Computing, Vienna, Austria. Available at https://www.R-project.org

Reid, F. 2006. Peterson field guide to mammals of North America. Fourth edition. Houghton Mifflin, New York, New York, USA.

Responsive Management. 2015. Trap use, furbearers trapped, and trapper characteristics in the United States in 2015. Conducted for the Association of Fish and Wildlife Agencies, Harrisonburg, Virginia, USA.

Ribic, C. A., D. M. Donner, A. J. Beck, D. J. Rugg, S. Reinecke, and D. Eklund. 2017. Beaver colony density trends on the ChequamegonNicolet National Forest, 1987-2013. PLoS ONE 12:e0170099.

Roberts, N. M. 2018. Otter population analyses. Wisconsin wildlife reports. Wisconsin Department of Natural Resources, Madison, USA.

Ruid, D. B. 2003. Assessment of four restraining devices for capturing beavers. Thesis, Utah State University, Logan, USA.

Rutter, A. U., A. T. Hanrahan, C. K. Nielsen, and E. M. Schauber. 2018. Survival and cause specific mortalities of river otters in southern Illinois. The American Midland Naturalist 180:160-167.

Sheldon, W. G., and W. G. Toll. 1964. Feeding habits of the river otter in a reservoir in central Massachusetts. Journal of Mammalogy 45:449-455.

Sun, L., D. Müller-Schwarze, and B. A. Schulte. 2000. Dispersal pattern and effective population size of the beaver. Canadian Journal of Zoology 78:393-398.

Swimley, T. J., R. P. Brooks, and T. L. Serfass. 1999. Otter and beaver interactions in the Delaware Water Gap National Recreation Area. Journal of the Pennsylvania Academy of Science 72:97-101.

Taylor, J. D., G. K. Yarrow, and J. E. Miller. 2017. Beavers. Wildlife Damage Management Technical Series. U.S. Department of Agriculture, National Wildlife Research Center, Fort Collins, Colorado, USA.

Tremblay, G., O. Valeria, and L. Imbeau. 2017. Characterization of beaver habitat parameters that promote the use of culverts as dam construction sites: can we limit the damage to forest roads? Forests 8:494.

U.S. Department of Agriculture. 2017. Program Data Report G-2017 Animals dispersed/killed or euthanized/removed or destroyed/freed. U.S. Department of Agriculture Animal and Plant Health Inspection Service, Riverdale, Maryland, USA. <https://www.aphis.usda.gov/aphis/ourfocus/ wildlifedamage/sa_reports/sa_pdrs/ct_pdr_home_2017> Accessed 25 Jan 2019.

Van Deelen, T. R. 1991. Dispersal patterns of juvenile beavers in Western Montana. Thesis, University of Montana, Missoula, USA.

Wisconsin Department of Natural Resources [WDNR]. 2002. Wisconsin trout streams. Wisconsin Department of Natural Resources, Madison, USA.

Wisconsin Department of Natural Resources [WDNR]. 2012. Wisconsin wetlands: county by county acreage. Wisconsin Department of Natural Resources, Madison, USA.

Zelin, S., J. C. Jofriet, K. Percival, and D. J. Abdinoor. 1983. Evaluation of humane traps: momentum thresholds for four furbearers. The Journal of Wildlife Management 45:863-868.

Associate Editor: Brainerd. 